\title{
The Functioning of a Removable Elongated Nozzle in the Hypersonic Aerodynamic Shock Tube
}

\author{
I.A. Ivanov ${ }^{1}$, M.A. Kotov ${ }^{2}$, L.B. Ruleva ${ }^{2}$ and S.I.Solodovnikov ${ }^{2}$ \\ Moscow State University, Russian Federation, Moscow \\ Institute for Problems in Mechanics, Russian Academy of Sciences, Russia, Moscow, 119526 \\ ivanovmai@mail.ru,ruleva@ipmnet.ru
}

\begin{abstract}
Presents the results of calculation and experimental research of an elongated nozzle block hypersonic aerodynamic shock tube of the laboratory of radiation gas dynamics IPMech RAS. The standard hypersonic conical nozzle was converted into an elongated nozzle with the form of the removable nozzle. The quasi-stationary gas flow through a new elongated nozzle block and the formation of a near-to-nozzle field of gas-dynamic parameters in a jet in a vacuum chamber are calculated. The braking pressures of the hypersonic flow at different distances from the nozzle section in the normal operation modes of the unit are experimentally measured. The calculated and experimentally measured braking pressures at the outlet of the elongated nozzle were compared, which showed a satisfactory match.
\end{abstract}

Keywords: hypersonic flow, nozzle, streamlines, numerical calculation, experiment.

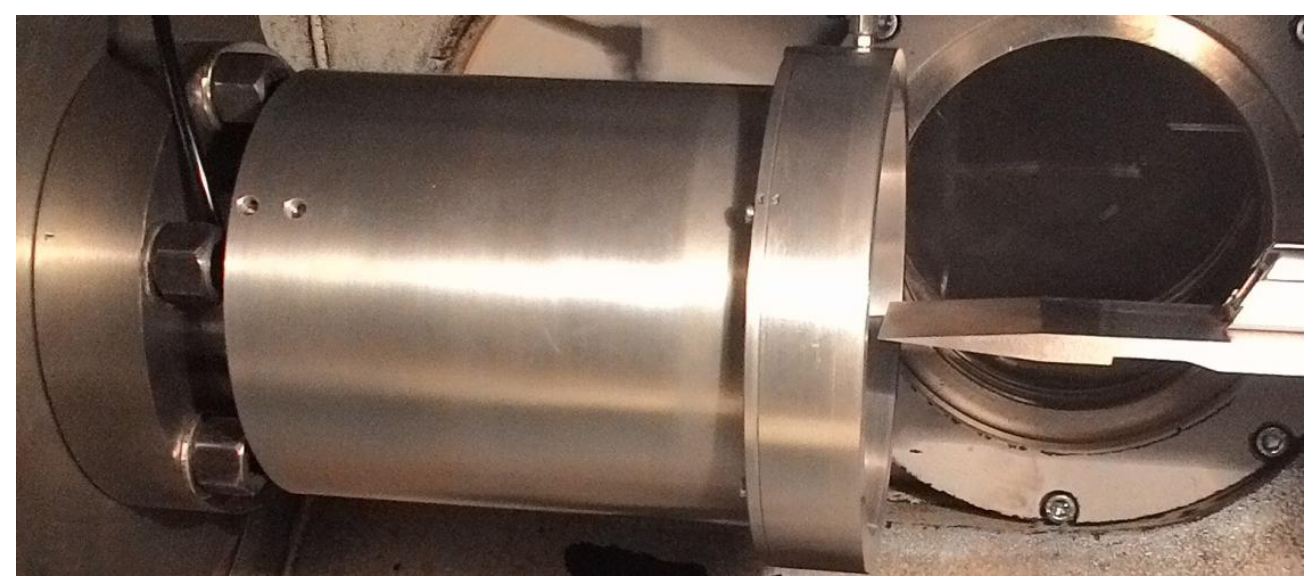

Elongated conical nozzle photo

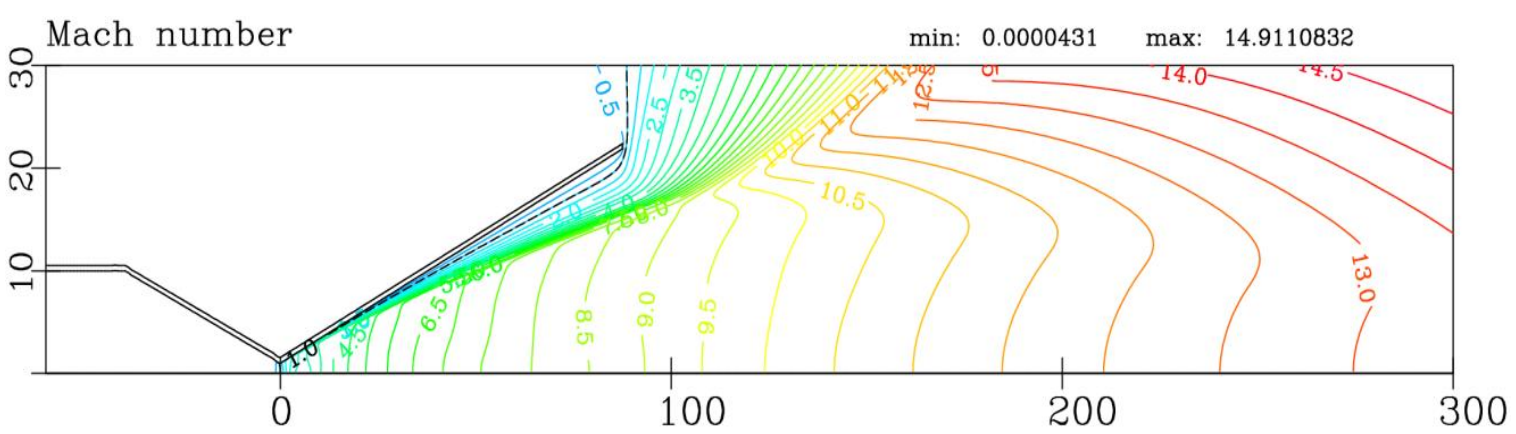

The calculation of the elongated conical nozzle 
УДК 539.9

\title{
Функционирование съемного удлиненного сопла гиперзвуковой ударной аэродинамической трубы
}

\author{
И.Э. Иванов ${ }^{1}$, М.А. Котов ${ }^{2}$, Л.Б. Рулева ${ }^{2}$, С.И. Солодовников ${ }^{2}$ \\ Московский государственный университет им. М.В. Ломоносова, Москва \\ Институт проблем механики им. А.Ю. Иилинского Российской академии наук, \\ Россия, Москва, 119526, проспект Вернадского, д.101-1, \\ ivanovmai@mail.ru,ruleva@ipmnet.ru
}

\begin{abstract}
Аннотация
Представлены результаты расчетно-экспериментальных исследований удлиненного соплового блока гиперзвуковой ударной аэродинамической трубы лаборатории радиационной газовой динамики ИПМех РАН. Изготовлен и испытан съемный раструб, преобразующий штатное гиперзвуковое коническое сопло в удлиненное сопло. Рассчитано квазистационарное истечение газа через новый удлиненный сопловой блок и формирование ближнего к соплу поля газодинамических параметров в струе в вакуумной камеpe. Экспериментально измерены давления торможения гиперзвукового потока на разных расстояниях от среза сопла в штатных режимах работы установки. Проведено сравнение рассчитанных и экспериментально измеренных давлений торможения на выходе удлиненного сопла, которое показало удовлетворительное совпадение.
\end{abstract}

Ключевые слова: гиперзвуковой поток, съемное удлиненное сопло, линии тока, численный расчет, эксперимент.

\section{1. Введение}

Продолжаются расчетно-экспериментальные исследования на гиперзвуковой ударной аэродинамической трубе (ГУАТ) лаборатории радиационной газовой динамики (РадГД) ИПМех РАН по обтеканию моделей летательных аппаратов (ЛА) газовыми потоками на гиперзвуковых скоростях. Штатное коническое гиперзвуковое сопло, исследованное в [1-4], используется в экспериментах в ГУАТ. Идея удлинения сопла вызвана как снижением пограничного слоя[5], так и возможностью наблюдения ударно-волновых структур на срезе сопла в иллюминаторе вакуумного блока.

Новое удлиненное гиперзвуковое коническое сопло образовано штатным соплом со съемным раструбом, которое продолжает внутреннюю коническую геометрию сопла без изъянов, которые могли бы нарушить линии тока струи. Измененная длина и диаметр выходного сечения нового сопла, при таком же угле раствора конуса, потребовала новых расчетно-экспериментальных исследований функционирования этой разработки.

Прямое численное исследование газодинамических процессов в полной конфигурации гиперзвуковой ударной аэродинамической трубе сопряжено с преодолением ряда проблем. Основная проблема связана с необходимость нестационарного расчета большого количества взаимодействующих газодинамических разрывов с учетом вязких явлений на очень подробных расчетных сетках. Последнее обусловлено большой протяженностью канала ударной трубы[2], ограниченной возможностью использования $1 \mathrm{D}$ расчетов, наличием дополнительной диафрагмы в горле сопла и разрешения пограничных слоев в трубе и сопловом блоке. 
Расчетно-экспериментальные исследования на установке ГУАТ условно делились на два этапа. На первом этапе рассматривались нестационарные процессы в тракте трубы (в камерах высокого и низкого давления) после открытия диафрагмы. Вопросы первого этапа рассмотрены в работах [2-4]. На следующем этапе численно моделировалось квазистационарное истечение газа через штатный сопловой блок [1] и формирование ближнего к соплу поля газодинамических параметров в струе в вакуумной камере.

Настоящая работа посвящена развитию расчетно-экспериментальных исследований на удлиненном сопле ГУАТ без удаления погранично слоя, описанного в [5].

\section{2. Схема ГУАТ и удлиненного сопла}

На схеме рис.1. показана установка ГУАТ, где удлинение сопла образовано раструбом, закрепленным на штатное сопло.

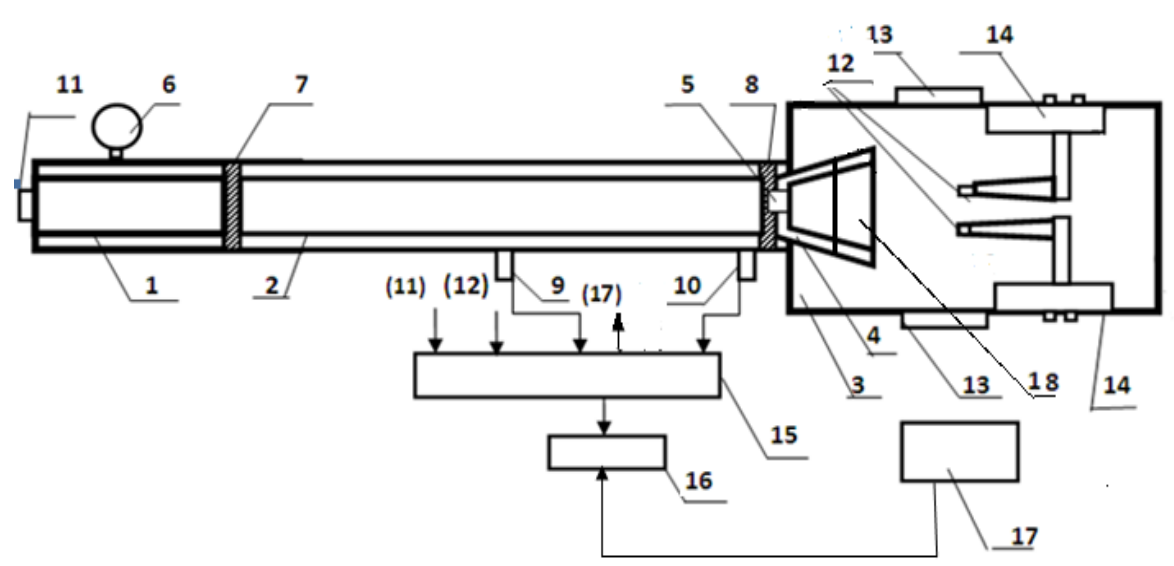

Рис.1. Схема ГУАТ

На схеме ГУАТ (рис.1) изображены: камера высокого давления 1, цилиндрический канал 2, вакуумная камера 3 и установленное в ней гиперзвуковое сопло 4 с критическим отверстием 5, манометр 6, электромагнитный быстродействующий клапан 7 , мембрана 8 , высокочастотные датчики динамического давления 9,10,11, 12, иллюминаторы 13, кронштейны (с моделями, либо с датчиками набегающего потока) 14, аналого-цифровые преобразователи 15, компьютер 16, высокоскоростная видеокамера 17, раструб 18.

Раструб 18 является продолжением гиперзвукового сопла 4 и вместе они составляют удлиненное коническое сопло с тем же углом раскрытия. Высоковакуумные насосы (откачные посты), системы смешивания и наполнения газов на рис.1. не показаны.

Критическая часть соплового блока размещена в ударной части тубы, имеет разъемную часть для установки мембраны 8 перед входом в сопло.

Упрощенный эскиз удлиненного конического сопла для нижеприведенных расчетов показан на рис.2.

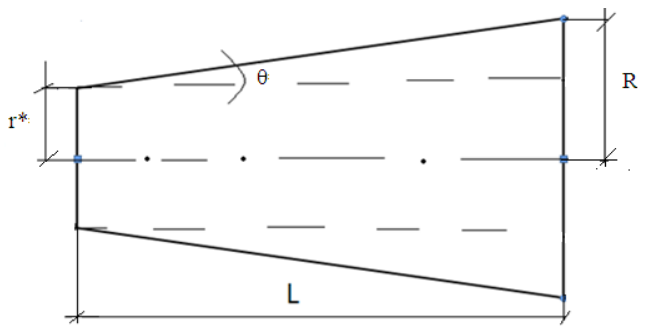

Рис.2. Эскиз конического сопла для расчетов 
Здесь $\mathrm{r}^{*}$ - радиус критического среза сопла, $\mathrm{R}$ - радиус выходного сечения сопла, $\mathrm{L}$ длина сопла, $\theta$ - угол полураствора конуса сверхзвуковой части сопла.

Виды части вакуумной камеры ГУАТ с коническими коротким (штатным) и удлиненным соплами показаны на рис. 3. и рис.4., соответственно.

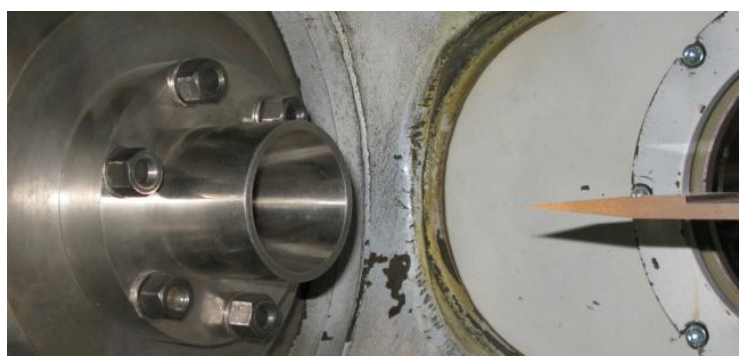

Рис. 3. Коническое штатное сопло ГУАТ

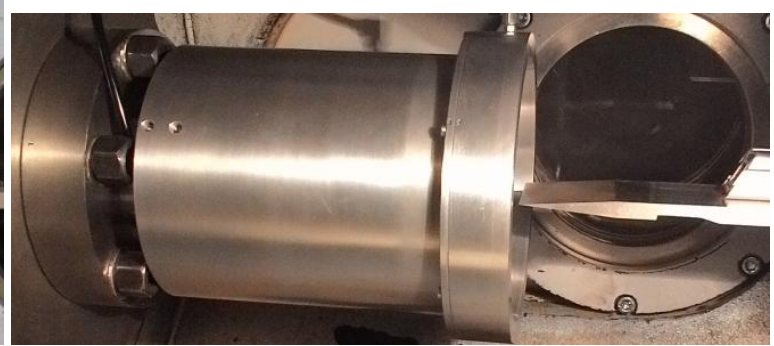

Рис.4. Удлиненное коническое сопло ГУАТ

Видно, что срез модернизированного сопла расположен в поле видимости смотрового окна, напротив которого устанавливается высокоскоростная видеокамера. Это расширяет функциональные возможности ГУАТ в экспериментах.

\section{3. Квазистационарный расчет удлиненного сопла ГУАТ}

Приведено численное моделирование стационарного течения вязкого газа в осесимметричном удлиненном сопле и струе. Решена система двумерных (осесимметричных) нестационарных уравнений Навье-Стокса, записанная в дивергентной форме, и дополненная уравнениями состояния идеального газа и граничными условиями на границах расчетной области. На границах, соответствующих твердым стенкам, заданы условия прилипания. На входе в сопло заданы полное давление и полная температура, на оси симметрии - условие непротекания, на удаленных границах - условия отсутствия отражения. Члены, описывающие конвективный перенос в данной системе, аппроксимированы с помощью модифицированной схемы Годунова высокого порядка точности [6]. Члены уравнений, описывающие диффузионный (вязкий) перенос аппроксимированы по схеме контрольного объема. Продвижение расчета по времени производилось с помощью метода Рунге-Кутта третьего порядка [6-8].

Расчеты проведены для стационарных режимов течения в удлиненном коническом сопле $(L=350$ мм) с выходным радиусом $R=87.5$ мм для различных значений давления на входе в сопло. Геометрическая степень расширения сопла равна:

$$
\left(\frac{R}{r^{*}}\right)^{2}=478.52
$$

На рисунках ниже показаны поле чисел Маха, и распределение чисел Маха вдоль оси симметрии сопла. Пространственные координаты отнесены к радиусу критического сечения. Радиус критического сечения сопла $r^{*}=4$ мм, давление на входе в сопло $P k=1.9$ атм, температура газа на входе в сопло $T k=820 \mathrm{~K}$. Число Рейнольдса, характеризующее течение вязкого газа в сопле, $\mathrm{Re}=6^{*} 10^{4}$ рассчитывается по параметрам в критическом сечении сопла и $r^{*}$.

Из-за большой длины сверхзвуковой части сопла на внутренней стенке нарастает большой пограничный слой (рис. 5.), который “оттесняет” поток от стенки и тем самым делает его более “одномерным”, но постоянно ускоряющимся вдоль направления оси " $\mathrm{x}$ ".

В выходном сечении поток истекает в среднем с числом Маха M=8.7 с достаточно высоким градиентом, направленным вдоль оси симметрии сопла (рис.6). 


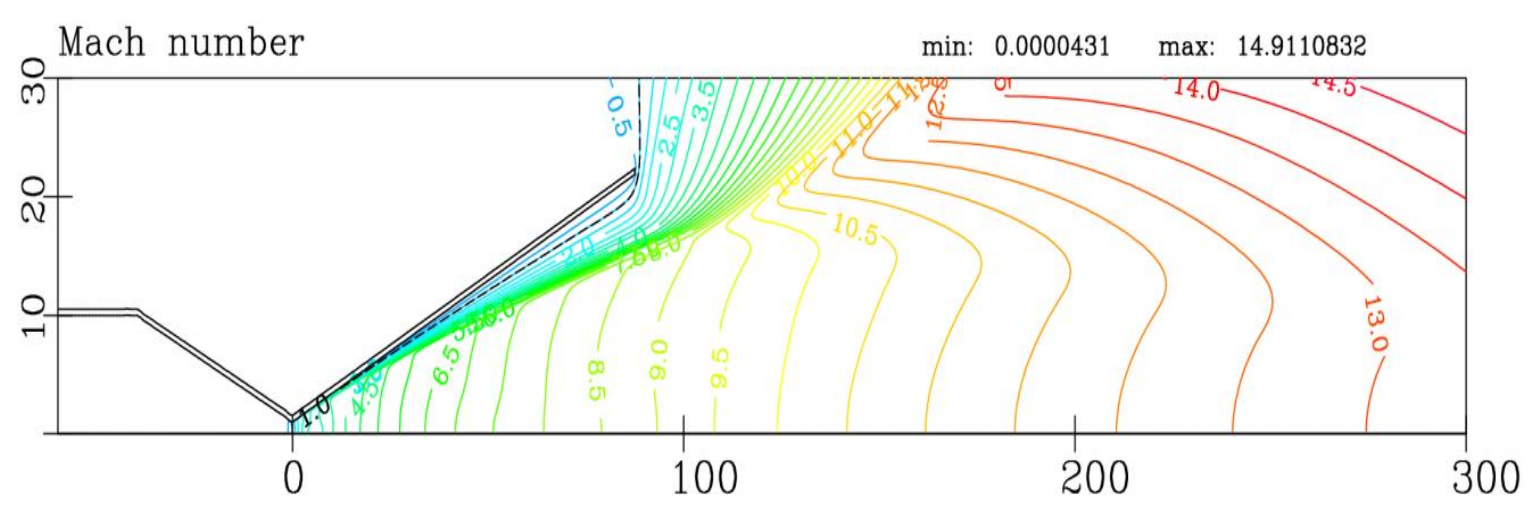

Рис. 5. Поле чисел Маха. Длинное коническое сопло, $P k=1.9$ атм., $r^{*}=4$ мм

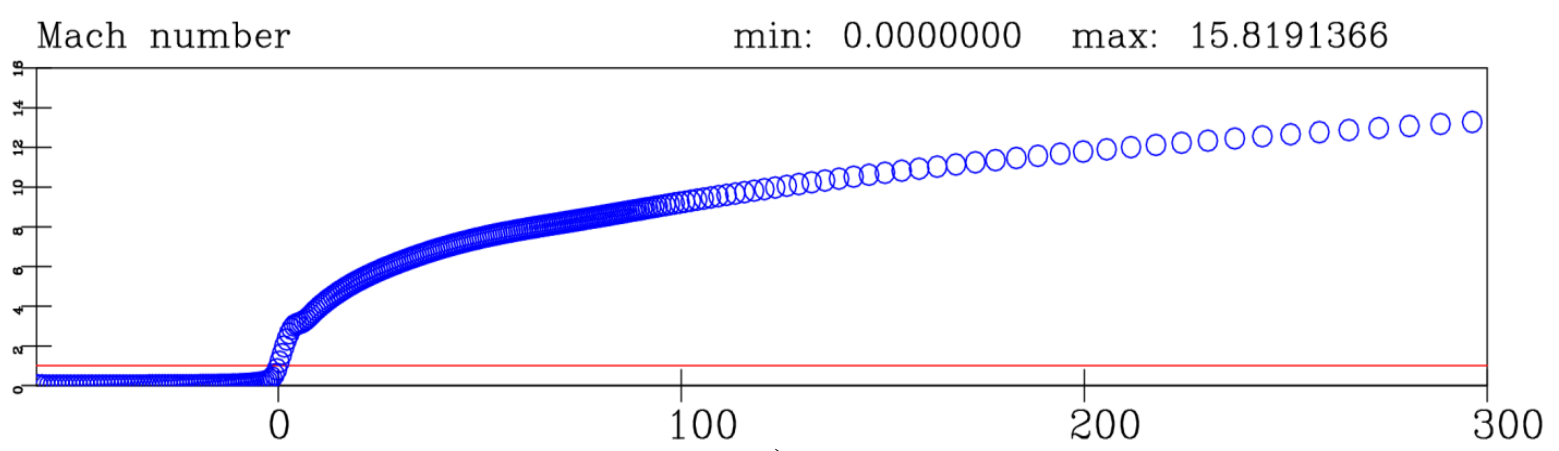

a)

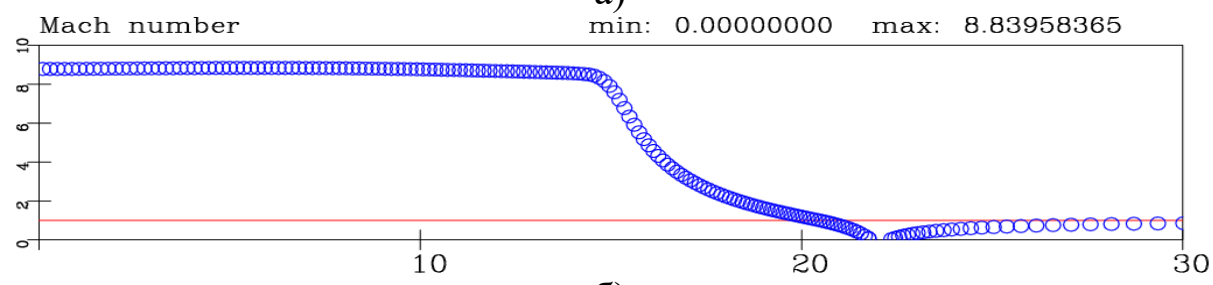

б)

Рис. 6. Длинное коническое сопло, $\mathrm{Pk}=1.9$ атм, $\mathrm{r}^{*}=4$ мм. Распределение чисел Маха вдоль оси сопла а) и вдоль среза сопла б)

Повышение давления на входе приводит к увеличению статического давления и плотности потока в внутри сопла, то есть увеличению числа Рейнольдса и уменьшению толщины пограничного слоя на стенке. Соответственно, уменьшение давления на входе в сопло способствует уменьшению числа Рейнольдса и увеличению толщины пограничного слоя. Нарастание пограничного слоя приводит к тому, что поток становится более равномерным в области влияния параметров на срезе сопла, то есть в области ограниченной срезом сопла и характеристиками, исходящими из кромок сопла до их пересечения с осью симметрии. На рис. 5 верхнюю границу области влияния можно отследить по излому линий уровня поля чисел Маха, который возникаем вблизи кромки сопла.

Векторное поле скорости и линий тока показаны на рис.7.

Из расчетов и из рис.5, рис. 6 б следует, что толщина пограничного слоя на срезе сопла равна $\delta=0.314 \mathrm{Rcp}=27.5$ мм,а толщина вытеснения $\delta^{*}=0.11 \mathrm{Rcp}=9.6$ мм.

Влияние давления на входе в сопло на величину угла скоса потока $\alpha=\operatorname{arctg}(\mathrm{v} / \mathrm{u})$, где $u, v$ - компоненты вектора скорости, на разных расстояниях от среза сопла, приведены в таблице 1. 


$\mathrm{t}=14.85977743 \quad \mathrm{res}=0.000000000000$

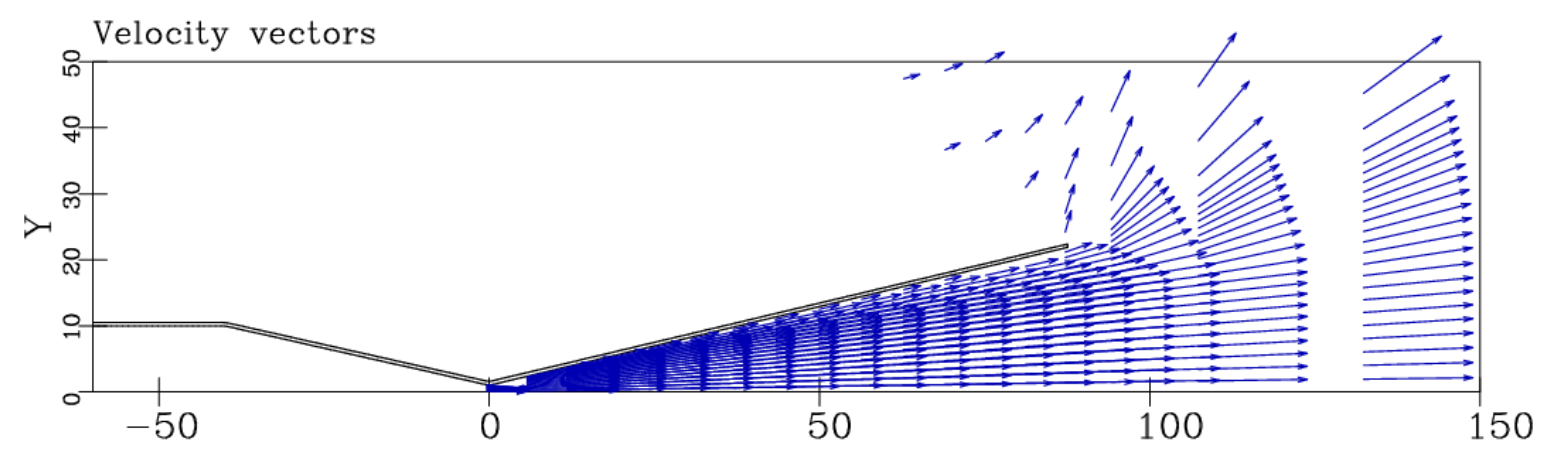

$t=14.85977743 \quad r e s=0.000000000000$

a)

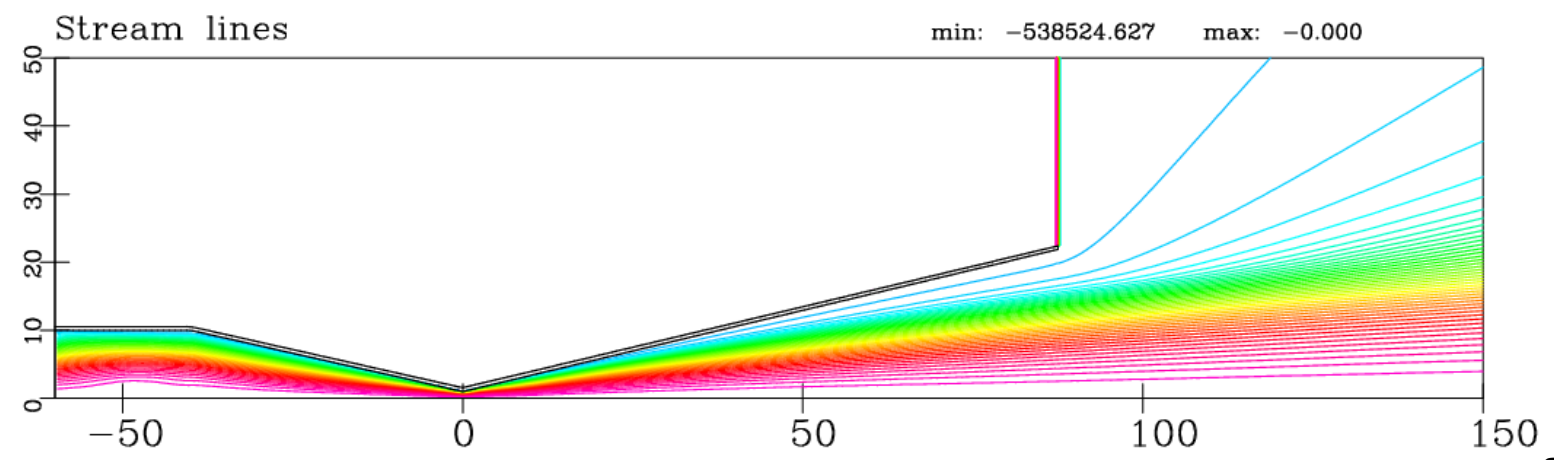

б)

Рис. 7. Вектора поля скорости а), линии тока б).

Таблица 1

Значение угла скоса потока $\alpha$ [градусы] В точке с ординатой $Y=0.044$ м на разных расстояниях от среза сопла.

\begin{tabular}{|c|c|c|c|}
\hline $\begin{array}{c}\text { Расстояние от } \\
\text { среза сопла, }\end{array}$ & $\mathrm{X}=0 \mathrm{M}$ & $\mathrm{X}=0.1337 \mathrm{M}$ & $\mathrm{X}=0.2534 \mathrm{M}$ \\
\hline$P k=1.9$ атм & $5.55^{\circ}$ & $4.05^{\circ}$ & $3.29^{\circ}$ \\
\hline$P k=3.0$ атм & $5.8^{\circ}$ & $4.26^{\circ}$ & $3.5^{\circ}$ \\
\hline
\end{tabular}

Из таблицы 1 следует, что с уменьшением давления на входе в сопло и увеличении расстояния от среза сопла угол скоса уменьшается.

\section{4. Сравнение расчетов с экспериментальными данными}

Проведены эксперименты по регистрации набегающего потока двумя одинаковыми датчиками давления, установленными в одной плоскости по оси конического удлиненного сопла и со сдвигом на 45 мм от оси (рис.8.).

Показания осевого датчика сравнивались с расчетом.

При давлениях перед критическим сечением сопла 1.9 атм и 3.88 атм приведены расчетные и экспериментальные данные давления торможения (Пито) по оси сопла на разных расстояниях от среза сопла в таблице 2. 


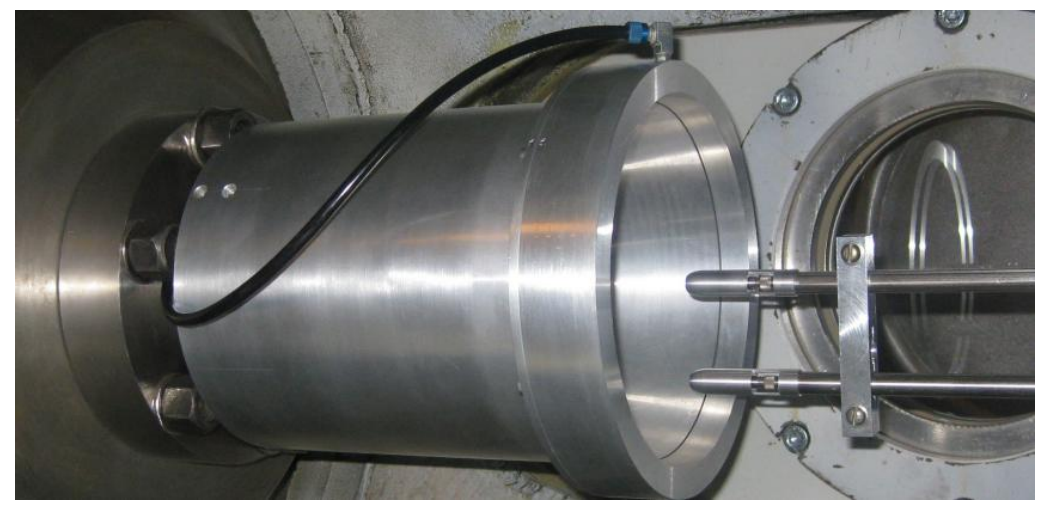

Рис.8. Датчики набегающего потока

Для измерения давления набегающего потока $P t$ за удлиненным соплом использовались сертифицированные высокочастотные датчики динамического давления РСВ $113 \mathrm{~B} 28$ (США). В эксперименте статическое давление за срезом сопла, которое в сотни раз меньше давления $P t$, не измерялось, из-за отсутствия однотипных датчиков низкого диапазона.

Область квазиравномерного потока за срезом конического сопла была экспериментально определена, путем измерения давления Пито, одномоментно, как по оси потока, так и со смещением на 45мм от оси потока (рис. 8). Графики давлений у критики и за срезом сопла показаны на рис.9.

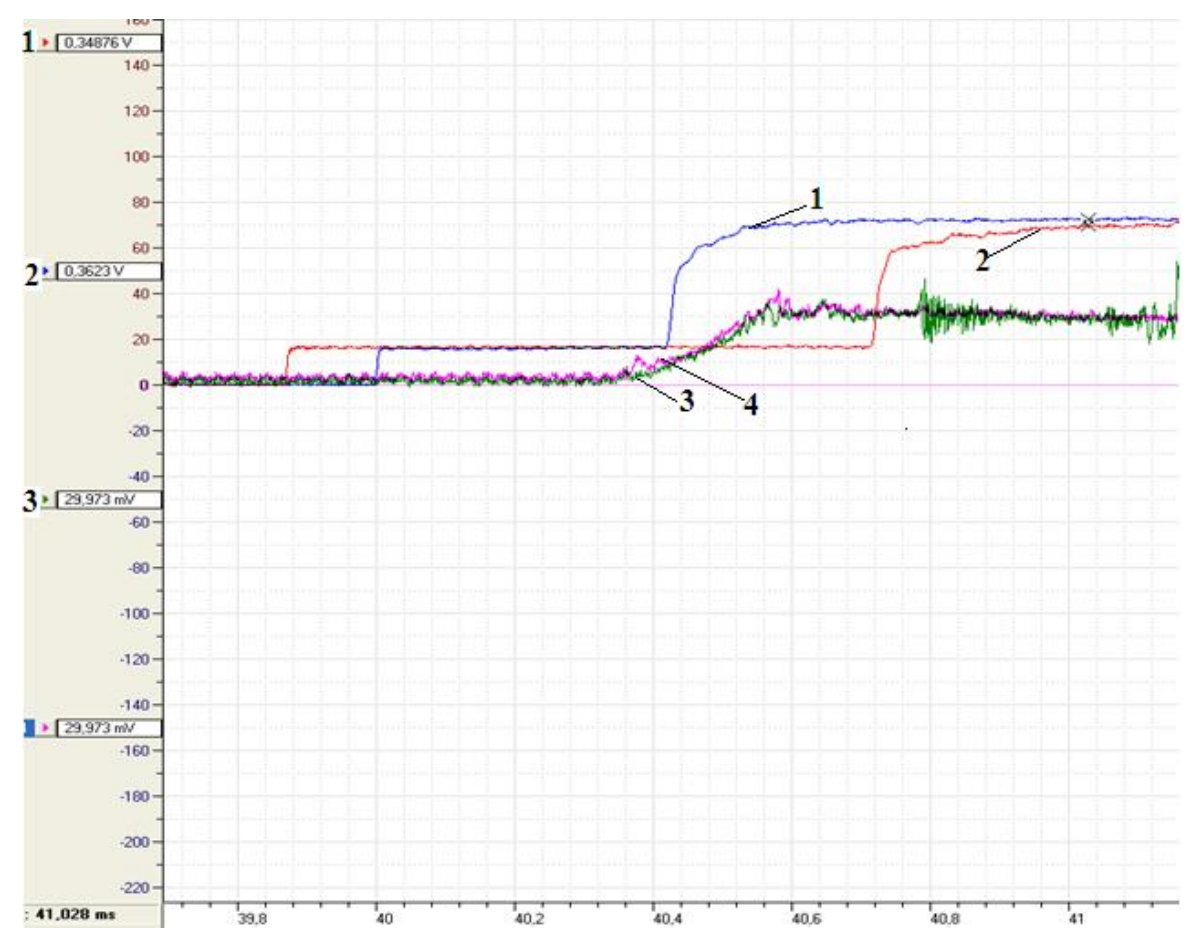

Рис.9. Графики давлений: 1,2,- за 200 мм и за 100 мм до критики сопла; 3,4 за соплом по оси и со сдвигом на 45мм от оси сопла, соответственно

Можно видеть, что при положении курсора на $41 \mathrm{~ms}$, показания 3 и 4 датчиков отличаются не более, чем на $1 \%$, что указывает на равномерность потока в области размещения модели за срезом сопла. 
Расчетные значения давления Пито на срезе удлиненного сопла

\begin{tabular}{|c|c|c|c|c|}
\hline $\begin{array}{c}\text { Distance from } \\
\text { the nozzle } \\
\text { exit, mm }\end{array}$ & $\begin{array}{c}P_{k p}=1,9 \text { aтм } \\
\begin{array}{c}P \text {-stagnation pres- } \\
\text { sure (Pitot), kPa. } \\
\text { Calculation. }\end{array}\end{array}$ & $\begin{array}{c}P_{\kappa p}=1.9 \text { атм } \\
P t \text {-stagnation pres- } \\
\text { sure (Pitot), kPa. } \\
\text { Experiment. }\end{array}$ & $\begin{array}{c}P_{\kappa p}=3.88 \text { атм } \\
P t \text {-stagnation pres- } \\
\text { sure(Pitot), kPa. } \\
\text { Calculation. }\end{array}$ & $\begin{array}{c}P_{k p}=3.88 \text { aтм } \\
P t \text {-stagnation pres- } \\
\text { sure (Pitot), kPa. } \\
\text { Experiment. }\end{array}$ \\
\hline 0 & 1.177 & 1.33 & 2.124 & 1.99 \\
\hline 25 & 1.069 & 1.12 & 1.906 & 1.90 \\
\hline 50 & 0.942 & 0.93 & 1.706 & 1.80 \\
\hline 75 & 0.852 & 0.86 & 1.540 & 1.56 \\
\hline 100 & 0.778 & 0.80 & 1.378 & 1.26 \\
\hline
\end{tabular}

\section{Заключение}

Расчетно-экспериментальное исследование функционирования удлиненного соплового блока гиперзвуковой ударной аэродинамической трубы лаборатории радиационной газовой динамики ИПМех РАН показали, что удлиненное коническое сопло пригодно для получения сверхзвукового потока на числа Маха $\mathrm{M=7..8}$. В отличие от штатного конического сопла, в изготовленном и испытанном удлиненном сопле поток более равномерный в области влияния параметров на срезе сопла. Сравнение рассчитанных полей течений с давлениями на выходе удлиненного сопла, измеренными экспериментально на разных расстояниях от среза сопла, показало удовлетворительное совпадение.

Дополнительные преимущества в использовании удлиненного сопла заключаются в возможности наблюдения структур течения на срезе сопла в смотровом окне и в возможности увеличения масштаба моделей перед коническим соплом.

\section{Благодарности и ссылка на гранты}

Работа выполнена в рамках Программы фундаментальных исследований РАН «Аэротермодинамика и навигация гиперзвуковых летательных аппаратов».

\section{Литература}

1. I. A. Ivanov, M. A. Kotov, I. A. Kryukov, L. B. Ruleva and S. I. Solodovnikov. Investigation of gas dynamic parameters of the conical nozzle block functioning in the Hypersonic Aerodynamic Shock Tube//Journal of Physics: Conf. Series 1009 (2018). http://iopscience.iop.org/article/10.1088/1742-6596/1009/1/012037/pdf

2. Kotov M.A., Kryukov I.A., Ruleva L.B., Solodovnikov S.I., Surzhikov S.T. Experimental Investigation Of An Aerodynamic Flow Of Geometrical Models In Hypersonic Aerodynamic Shock Tube // AIAA 2013-2931, 14 p.

3. Котов М.А., Рулева Л.Б., Солодовников С.И., Суржиков С.Т.Исследование ударно-волновых процессов обтекания клиновидных моделей с кавернами в гиперзвуковой ударной аэродинамической трубе //http://chemphys.edu.ru/issues/2014-15-3/articles/223

4. Котов М.А., Рулева Л.Б., Солодовников С.И., Суржиков С.Т. Обтекание сферических и конических объектов в гиперзвуковой ударной аэродинамической трубе. Физико-химическая кинетика в газовой динамике //http://chemphys.edu.ru/issues/2014-15-1/articles/107/

5. Рулева Л.Б., Котов М.А., Солодовников С.И. Сверхзвуковое осесимметричное сопло. Патент № 181016 от 03.07.2018 г. Б.И.№ 19. 
6. Годунов С.К., Забродин А.В., Иванов М.Я., Крайко А.Н., Прокопов Г.П. Численное решение многомерных задач газовой динамики. - М.: Наука, 1976, 400 с.

7. Иванов И.Э., Крюков И.А. Квазимонотонный метод повышенного порядка точности для расчета внутренних и струйных течений невязкого газа // Математическое моделирование, том 8 , № 6, 1996, С.47-56.

8. Глушко Г.С., Иванов И.Э., Крюков И.А. Метод расчета турбулентных сверхзвуковых течений. Математическое моделирование, 2009, том 21, № 12, с.103 - 121.

Статья поступила в редакцию 8 октября 2018 г. 